\title{
MOVIMENTO NACIONAL DE POPULAÇÃO DE RUA: A COMPLEXA LUTA POR DIREITOS
}

\author{
HOMELESS PEOPLE NATIONAL MOVEMENT: THE COMPLEX STRUGGLE FOR RIGHTS \\ MOVIMIENTO NACIONAL DE POBLACIÓN DE CALLE: LA COMPLEJA LUCHA POR DERECHOS
}

\author{
Aline Amaral Sicari* \\ Andrea Vieira Zanella ${ }^{* *}$
}

\begin{abstract}
RESUMO
A pesquisa objetivou investigar as tensões e paradoxos que caracterizam a luta do Movimento Nacional de População de Rua (MNPR). Foi foco da pesquisa uma unidade do movimento, de uma cidade de médio porte do Sul do Brasil. O material analisado foi produzido com base na participação em reuniões do MNPR e em conversas formais e informais com 25 pessoas em situação de rua e, ou, trajetória de rua. A análise dialógica do discurso foi a escolha metodológica para a pesquisa. Foram identificados cinco paradoxos: 1) a condição de incômodo e, ao mesmo tempo, de reconhecimento da importância do lugar ocupado pela liderança do movimento; 2) a tensão entre estar nas ruas e estar nos espaços institucionalizados de luta; 3) a contradição entre projetos de vida singulares e a necessidade de luta por mudanças para todos, todas; 4) a tensão visibilidade e invisibilidade das pessoas em situação de rua; 5) a contradição entre viver nas ruas e poder/ querer sair dessa condição, com o risco de não ser mais reconhecido(a) pelos pares e participar de sua luta. Apesar dos paradoxos, a pesquisa destaca a importância do MNPR na luta por direitos sociais, políticos e humanos em favor da população em situação de rua.
\end{abstract}

Palavras-chave: Pessoas em situação de rua. Movimento Nacional de População de Rua. Movimento social. Direito.

\footnotetext{
Texto recebido em 23 de setembro de 2019 e aprovado para publicação em 23 de setembro de 2019.

"Mestra em Psicologia Social e Cultura pela Universidade Federal de Santa Catarina (UFSC), especialista em Educação em Direitos Humanos pela Faculdade de Educação da Universidade Federal de Uberlândia (UFU), graduada em Psicologia pela UFU. Endereço: Avenida Israel, 1163, casa 240 - Laranjeiras, Uberlândia-MG, Brasil. CEP: 38410-264. Telefone: (34) 98834 6974. E-mail: alinesicari@hotmail.com

** Doutora e mestra em Psicologia da Educação pela Pontifícia Universidade Católica de São Paulo (PUC-SP), docente permanente no Programa de Pós-Graduação em Psicologia da UFSC, professora titular aposentada da UFSC, graduada em Psicologia pela Universidade Federal do Paraná (UFPR), realizou estudos pós-doutorais na Università Degli Studi di Roma La Sapienza e na Universidade Federal do Rio Grande do Sul (UFRGS), foi pesquisadora visitante da New School for Social Research em 2016. Endereço: Universidade Federal de Santa Catarina, Centro de Filosofia e Ciências Humanas, Departamento de Psicologia. UFSC - CFH - Departamento de Psicologia - Trindade, Florianópolis-SC, Brasil. CEP: 88010-970. Telefone: (48) 3721-8566. Fax: (48) 3721-9984.
} 


\section{ABSTRACT}

The research aimed to investigate the tensions and paradoxes that characterize the struggle of the Homeless People National Movement (MNPR, the acronym in Portuguese). Its focus was a unit of the movement, located in an average city in the south of Brazil. Data analyzed were gathered during the participation in MNPR meetings and formal and informal conversations with 25 homeless people, or people with a homelessness experience. Dialogical interaction analysis was the methodology of choice. Five paradoxes were identified: 1) the condition of discomfort, concurrent with recognizing the importance of the place occupied by the movement's leadership; 2) the tension between being on the streets and being in the institutionalized spaces of struggle; 3) the contradiction between singular life projects and the need to fight for change concerning all; 4) the tension, visibility and invisibility of homeless people; 5) the contradiction between living on the streets and being able/willing to get out of this condition, with the risk of not being recognized by peers and not taking part in the struggle. Despite the paradoxes, the research highlights the importance of MNPR concerning the fight for social, political and human rights to homeless people.

Keywords: Homeless people. National Movement of Homeless People. Social movement. Rights.

\section{RESUMEN}

La investigación tuvo como objetivo investigar las tensiones y paradojas que caracterizan la lucha del Movimiento Nacional de Población de la Calle (MNPR). El foco de la investigación fue una unidad del movimiento en una ciudad de mediano porte del sur de Brasil. El material analizado fue producido a través de la participación en reuniones del MNPR y de conversaciones formales e informales con 25 personas en situación de calle y / o trayectoria de calle. El análisis dialógico del discurso fue el eje metodológico de la investigación. Se identificaron cinco paradojas: 1) la condición de incomodidad y, al mismo tiempo, reconocimiento de la importancia del lugar ocupado por la dirección del movimiento; 2) la tensión entre estar en las calles y estar en los espacios institucionalizados de lucha; 3 ) la contradicción entre proyectos de vida singulares y la necesidad de luchar por el cambio para todos; 4) la tensión entre visibilidad e invisibilidad de las personas en situación de calle; 5) la contradicción entre vivir en la calle y poder/querer salir de esta condición, con el riesgo de no ser reconocido por sus compañeros y participar en su lucha. A pesar de las paradojas, resaltamos aún la importancia del MNPR en la lucha por derechos sociales, políticos y humanos de la población en situación de calle.

Palabras clave: Personas en situación de calle. Movimiento Nacional de Población de la calle. Movimiento social. Derecho. 


\section{INTRODUÇÃO}

$\mathrm{N}$ este artigo, são apresentados alguns resultados de uma pesquisa realizada com pessoas em situação de rua a respeito dos processos de visibilidade e invisibilidade que a elas se dirigem na cidade (Sicari, 2018). Entre as várias questôes apresentadas pelos participantes da investigação, uma delas mereceu destaque no relatório da pesquisa, em razão de sua complexidade e dos paradoxos que engendra: a luta por direitos de pessoas que vivem em situação de rua.

A militância no Movimento Nacional de População de Rua (MNPR) se dá por luta árdua, que confronta diretamente as práticas governamentais e vem provocando mudanças. O "nada sobre nós [. . .] sem nós”, lema do MNPR, visa a reivindicar o direito à participação na construção de políticas públicas que a elas se destinam bem como reafirmar sua existência como sujeitos conscientes e críticos, que estão dispostos a ocupar seus lugares de fala, transformar suas realidades e necessidades, compartilhar seus saberes e seus conhecimentos sobre a vida nas ruas. É um lema que convoca à inclusão das pessoas em situação de rua em todas as instâncias políticas, sociais e culturais.

Em âmbito nacional, Almeida (2015) e Melo (2015) apontam que a consolidação do MNPR alterou a relação que estava estabelecida entre governo e a sociedade, passando a considerar a "existência de um espaço de fala e reconhecimento das pessoas em situação de rua enquanto interlocutores válidos no campo de disputas políticas e nas questôes que se referem à vida em situação de rua" (Melo, 2015, p. 200). Almeida (2015) evidencia que houve a transposição das práticas hegemônicas de caridade, na maioria das vezes vinculadas a instituições religiosas, para ações do Estado, legitimando a existência e as necessidades das pessoas em situação de rua.

A organização política dessas pessoas configura-se como uma forma de renovar as possibilidades de vida, de transformar "condutas marcadas pela necessidade em criatividade para dar resolução ao leque de dificuldades que se afigura" (Melo, 2015 , p. 202). Mas essa organização, concretizada via MNPR, é marcada por uma série de dificuldades, sejam relativas às pautas de luta propriamente e aos vários outros com os quais se confrontam, sejam relativas aos pares e ao processo de sua própria constituição como coletivo organizado. Tensões constantes se evidenciam, sendo estas foco deste artigo. A partir da participação em reuniões de um polo estadual do movimento e da escuta de pessoas em situação de rua, permitiu-se compreender o MNPR como um movimento social complexo, constituído por embates, tensionamentos, ambivalências e paradoxos. 
Apresentaremos, a seguir, o modo como a pesquisa foi desenvolvida: método; um breve resgate histórico do surgimento do MNPR no Brasil e no polo em que se pesquisou; os discursos das pessoas em situação de rua sobre o movimento; e, por fim, reflexões finais sobre o tema em questão.

\section{MÉTODO}

Compreendendo que pesquisar em Psicologia Social Crítica consiste em problematizar as relações sociais que se estabelecem em determinado contexto, o pesquisador constitui-se como um interventor implicado, o que significa assumir que é também objetivado pelo que busca objetivar, colocando as próprias implicaçôes em análise (Aguiar, \& Rocha, 2007; Paulon, 2005; Rocha, \& Aguiar, 2003).

Considerando isso, a pesquisa foi realizada em uma capital do Sul do País e iniciou a partir da aproximação com pessoas em situação de rua, por meio da participação em reuniōes semanais do MNPR. Percebendo a necessidade de ampliar o campo de pesquisa para além dessas reuniões, a construção da pesquisa passou a ocupar as ruas do centro e a praça principal da cidade, locais em que há maior concentração de pessoas em situação de rua. A pesquisadora frequentou esses locais três vezes por semana, durante um ano, na maioria das vezes no período da tarde e, esporadicamente, à noite. Participaram da investigação 25 pessoas em situação de rua e, ou, que já estiveram em situação de rua em algum período de suas vidas, ${ }^{1}$ sendo 20 pessoas do sexo masculino e 5 do sexo feminino, com idades entre 22 e 60 anos, com tempo em situação de rua variados: alguns estavam havia poucos meses vivendo nas ruas, outros estavam havia anos.

No decorrer da convivência com as pessoas em situação de rua nos locais em que passavam o dia, no centro da cidade e nas reuniōes do MNPR, foram realizadas conversas individuais e grupais, tanto formais como informais, compreendidas como práticas discursivas em que construímos as informações contextualizadas por meio de um diálogo, sem perguntas predefinidas, mas com uma intencionalidade. Algumas dessas conversas foram gravadas em áudio e posteriormente transcritas. As conversas não gravadas em áudio foram registradas em diário de campo.

A análise dialógica do discurso foi a escolha metodológica para a pesquisa, a qual compreende a constituição do ser humano a partir da relação dialógica e dialética com um outro (Bakhtin, 2011). Orientada pelas contribuições de Bakhtin e seu círculo, essa perspectiva de análise considera que

1 A realização da pesquisa foi aprovada pelo Comitê de Ética em Pesquisa com Seres Humanos (CEPSH) da UFSC, sob o parecer de número 1.995.924. 
O conhecimento: nunca será final (ístina), mas sempre situado, datado, localizado e entoado por alguém (pravda); o caráter singular é que ocupa lugar de destaque, e não as regularidades e universalidades; é dialógico, pois a alteridade constitui-se como fundadora do eu - não é possível pensar o sujeito a partir de uma ótica individualista, tomado em separado do outro, e por conseguinte não é possível pensar a pesquisa desconsiderando os muitos outros participantes do diálogo e do processo de produção de sentidos do qual o/a pesquisador/a se apresenta como partícipe (Machado, \& Zanella, 2019, p. 14)

A análise dos materiais produzidos no decorrer da pesquisa, por conseguinte, realizada em diálogo com as contribuições de Bakhtin e os aportes teóricos da Psicologia Histórico-Cultural de Vigotski, considerou que todo e qualquer texto "só tem vida contatando com outro texto (contexto). Só no ponto desse contato de textos eclode a luz que ilumina retrospectiva e prospectivamente, iniciando dado texto no diálogo" (Bakhtin, 2011, p. 401). Os textos que aqui apresentamos em diálogo são provenientes tanto de documentos e pesquisas que analisam a história do MNPR no Brasil como dos discursos de pessoas em situação de rua que surgiram de contextos variados: reuniōes do movimento, em eventos que seus integrantes participaram e das conversas com pessoas em situação de rua, realizadas no decorrer da pesquisa.

\section{BREVE HISTÓRICO DO MNPR NO BRASIL E NO POLO ESTADUAL PESQUISADO}

O Movimento Nacional de População de Rua (MNPR), presente no Brasil desde 2004, tem como uma de suas premissas a inclusão de pessoas em situação de rua na discussão de qualquer assunto que esteja relacionado a elas, exige o fazer "com". Assim, têm como lema a máxima de "nada sobre nós, sem nós": uma forma de reivindicar seus lugares de fala, considerando a experiência de vida na rua como fundamental para se pensar e construir ações direcionadas a essa população.

O estopim para o surgimento da organização em âmbito nacional foi o evento trágico que ficou conhecido, nacional e internacionalmente, como "Massacre da Praça da Sé", ocorrido entre os dias 19 e 22 de agosto de 2004, na cidade de São Paulo, quando 15 pessoas em situação de rua foram agredidas e 7 delas faleceram (Freitas, 2016; Melo, 2016). De acordo com Melo (2016) e De Lucca (2016), a investigação em relação aos culpados pelo crime ainda não foi finalizada, o que potencializa o sentimento de injustiça por parte dos militantes do MNPR. Tem-se a suspeita de que a ação criminosa foi realizada por policiais e seguranças privados, a mando de comerciantes da área, que estavam insatisfeitos com a presença de pessoas em situação de rua na região central da cidade (Melo, 2016). 
A partir desse acontecimento, constituiu-se o Fórum Nacional de Estudos sobre a População de Rua que, em conjunto com outras instituições sociais, formulou a criação do Movimento Nacional da População de Rua (MNPR). O movimento foi consolidado oficialmente no $4^{\circ}$ Encontro Nacional Lixo e Cidadania, em 2005, tendo como pauta principal a luta contra a violência e a impunidade (Melo, 2016). Essa pauta ampliou-se com as lutas em prol da construção de políticas públicas para pessoas em situação de rua e a participação na fiscalização dessas (Almeida, Medeiros, \& Barbosa, 2014; Conselho Federal de Psicologia, 2015). Em 2005, ocorreu o I Encontro Nacional de População em Situação de Rua, que culminou na expansão do movimento pela luta por direitos dentro do território nacional (Conselho Federal de Psicologia, 2015; Freitas, 2016).

A organização política das populações em situação de rua foi fundamental para provocar o Estado a elaborar políticas públicas referenciadas a essa população, mesmo que ainda incipientes (Conselho Federal de Psicologia, 2015). A criação da Política Nacional para População em Situação de Rua, em 2009 (Decreto no $7.053,2009),{ }^{2}$ configura-se como um marco legal às políticas para a população em situação de rua e surge como resultado da pressão exercida pelo MNPR (Almeida, 2015; Almeida et al., 2014). A elaboração dessa política pública ocasionou o fortalecimento político e organizativo das pessoas em situação de rua, pois estas passaram a se reconhecer como pessoas de direitos e se aproximaram do movimento social (Melo, 2015).

Atualmente, o MNPR está presente em 14 Estados brasileiros e tem como objetivo geral o resgate de autonomia, por meio do trabalho digno, moradia, qualidade salarial e acesso à saúde e assistência social (Almeida et al., 2014). Além da publicação do Decreto no $7.053 / 2009$, é possível apontar outras conquistas do movimento social, como a adaptação para o preenchimento do Cadastro Único para Programas Sociais do Governo Federal (CadÚnico) às pessoas em situação de rua. Para completar o cadastro no CadÚnico, era necessário apresentar um endereço fixo e descrever o domicílio em que a pessoa residia, o que automaticamente impedia o cadastro de pessoas em situação de rua. A partir do diálogo do MNPR com o governo federal, foram realizadas modificações na ficha de cadastro, acrescentando a categoria "pessoas em situação de rua" no momento em que se fazia necessário descrever o domicílio, com a permissão do uso do endereço de equipamentos de assistência social como endereço de referência (Melo, 2015; Melo, 2016).

2 O Decreto no 7.053/2009 define conceitualmente o que é população de rua com o objetivo de orientar e direcionar políticas públicas a essa população. O MNPR atualmente tem como uma das pautas de luta a transformação desse Decreto em Lei, com o objetivo de garantir a permanência dessa política independente do governo em atuação (Almeida, 2015). 
$\mathrm{Na}$ cidade pesquisada, a consolidação do MNPR ocorreu em 2012. De forma semelhante ao surgimento do movimento nacional, a mobilização adveio após a morte de duas pessoas em situação de rua. Se as mortes em São Paulo, em 2004, foram ocasionadas devido à violência física, na cidade em que realizamos a pesquisa, as duas mortes foram marcadas pela violência institucional, decorrente da ausência do Estado e de estratégias de cuidado e sobrevivência que protegessem pessoas em situação de rua durante o inverno na cidade. As baixas temperaturas e a ausência de instituições de acolhimento para pernoite, como albergues municipais, provocou a morte de duas pessoas que não suportaram dormir ao relento, que não tiveram chances de se aquecer, o que culminou na organização política das pessoas que viviam em condição de rua na cidade.

A estruturação desse polo estadual do MNPR surgiu com o objetivo inicial de pressionar o governo da cidade a aderir à Política Nacional de População em Situação de Rua, estabelecida pelo Decreto no 7.053/2009, cujo foco estava principalmente na necessidade emergencial de albergues. A pressão política foi realizada por meio da ocupação do prédio da Secretaria Municipal de Assistência Social, no mesmo mês em que as mortes foram registradas, por cerca de 30 pessoas em situação de rua. A reivindicação inicial daquele grupo de pessoas foi atendida por intermédio de uma reunião na Câmara de Vereadores, na qual se deliberou pela abertura de um albergue municipal e constituição do Comitê Intersetorial de Acompanhamento e Monitoramento da Política Nacional da População em Situação de Rua. A partir de então, foi iniciada uma organização política, com a realização de reuniōes semanais e denúncias em relação a violações de direitos, o que constituiu o MNPR representante do Estado em que se realizou a pesquisa.

Almeida (2015) afirma que a organização do MNPR se diferencia em cada Estado e que esse processo está relacionado ao tempo de existência e à conjuntura social do local. Apesar da autonomia dos polos estaduais do MNPR, de dois em dois anos, é realizado o Congresso Nacional do MNPR, espaço em que são eleitos, em plenária, os representantes nacionais e estaduais, e são discutidas pautas de interesses comuns. O I Congresso Nacional do MNPR foi realizado em 2012, em Salvador, Bahia; o segundo, em 2014, em Curitiba, Paraná; e o terceiro, em Belo Horizonte, Minas Gerais, em 2016.

"A gente não negocia direito" é a frase que ecoa em quase todas as falas que os militantes do MNPR realizam nos eventos que promovem e que são convidados a participar. Configura-se como necessário explicitar essa premissa, que os respalde de qualquer artimanha política que tente manipular a conquista de direito, ao mesmo tempo em que deixa perceptível seus objetivos de luta: direitos.

É oportuno salientar que o MNPR provoca mudanças políticas e sociais, mas 
também atua diretamente no modo de vida das pessoas que se envolvem nele, o que fica perceptível na fala de um participante do movimento ao afirmar que o MNPR é "uma ferramenta que tá nos proporcionando uma qualidade de vida" (Diário de campo, fala de Saulo, ${ }^{3}$ junho de 2017).

\section{RESULTADOS E DISCUSSÃO: O MNPR SEGUNDO AS PESSOAS EM SITUAÇÃO DE RUA}

De acordo com De Lucca (2016), o MNPR é um movimento social que se constitui em uma arena de ambivalências e paradoxos. A própria criação do MNPR é marcada por contradições, pois foi a partir de um episódio trágico de violência brutal que as pessoas em situação de rua se organizaram. Conforme mencionado, a chacina de pessoas em situação de rua na Praça da Sé, em São Paulo, no ano de 2004, foi o episódio que impulsionou a organização social e política das pessoas que vivem nas ruas (Freitas, 2016). Ou seja, de um acontecimento hediondo, foi "possível perceber o investimento em uma produção de memória e identidade" (Melo, 2016, p. 58), circunscrevendo a existência de algo potente que apenas foi possível existir a partir dessa situação.

De Lucca (2016) aponta que, historicamente, o MNPR está ligado à qualidade de vítima, de sofredor de diversos tipos de violência, o que, de certo modo, o estigmatiza perante os contextos políticos e públicos que ocupa. $\mathrm{O}$ fato de buscarem o reconhecimento das condiçôes indignas de vida nas ruas, ao mesmo tempo em que se reconhecem como sujeitos dignos, ou seja, o fato de lutarem "simultaneamente pela valorização das vidas de rua e por sua abolição, sendo assim, paradoxalmente, 'a favor' e 'contra' a existência de vidas de rua" (De Lucca, 2016, p. 37), demarcam os lugares opostos que ocupam. Ao mesmo tempo, esses pontos convergem, configurando o MNPR como um movimento social complexo, composto por contradiçôes, ambiguidades, adversidades e tensionamentos.

Durante a pesquisa realizada, foi possível identificar alguns questionamentos insolúveis que alimentavam reflexões críticas quanto ao próprio movimento, seus modos organizativos e suas contradiçôes. Esses questionamentos se direcionavam ao movimento, mas estavam diretamente relacionados à vida pessoal de cada militante. Por exemplo: em uma das reuniões do MNPR, estava em pauta a pouca adesão das pessoas em situação de rua nas atividades do movimento. Um dos militantes pontuou:

3 Os nomes dos participantes da pesquisa utilizados neste artigo são fictícios. 
Tô me sentindo instituição. A área de confronto não é aqui [referindo-se ao local institucionalizado que a reunião era feita], é lá [referindo-se à rua e à praça central da cidade]. Por que temos que esperar os companheiros passar por um processo pra aderir ao movimento? Por que não podemos ir onde essas pessoas estão? (Diário de campo, fala de Saulo, maio de 2017)

A fala de Saulo, participante da pesquisa e coordenador estadual do MNPR, homem, 39 anos, dos quais 15 anos foram vividos em situação de rua, enuncia o sentimento de institucionalização de seu modo de existir; carrega o descontentamento de se sentir dessa forma e apresenta o fardo pesado de se enxergar como instituição. O lamento de vivenciar esse sentimento, de partilhar algo diferente do que escolheu para sua vida, coloca o sujeito em um lugar paradoxal. Ser institucionalizado, sentir-se instituição, é estar acorrentado a algo, o que se contrapõe ao que leva muitas pessoas a viver nas ruas, ou seja, o desejo de romper com normas sociais e viver em liberdade, desacorrentado de amarras sociais. Ocupar as ruas da cidade, esse lugar considerado socialmente como marginal, escancara diferentes formas de viver que negam os regulamentos sociais e não tem afinidade com nenhum tipo de instituição.

Entretanto, para ocupar a função de coordenador estadual, para ampliar a rede de parcerias do MNPR, para conquistar uma representatividade de espaços políticos, foi necessário, para Saulo e tantas outras pessoas que ocupam lugares similares, institucionalizar-se. Como militante do movimento, ele teve de deixar o espaço da rua e ocupar espaços institucionais, a fim de garantir a existência e lutar pela organização do movimento social. Assim, a fala de Saulo enuncia o que consideramos como um primeiro paradoxo, que diz respeito ao modo como vivenciava, na condição de coordenador do movimento, essa questão: o incômodo e, ao mesmo tempo, o reconhecimento da importância de sua postura no movimento.

Por se configurar como incoerente com suas concepções de mundo, de vida e de existência, ocupar esse lugar fez com que ele problematizasse o modo como se sentia e atuava, sem deixar de reconhecer que, para dar continuidade na busca por direitos das pessoas em situação de rua, precisou se amarrar a uma instituição, vincular-se a um movimento social organizado que tem como uma das pautas garantir a existência de pessoas desinstitucionalizadas.

Para Maheirie (2008), os movimentos sociais "trazem em si a ambiguidade de ser o que são, como negação da negação, produto e produtores da sociedade que ora legitimam, ora resistem" (p. 52). Além de incorporarem formas tradicionais de realizar política, para a autora, os movimentos sociais praticam, em alguns momentos, aquilo que lutam contra. Isso é visível com o MNPR: um movimento 
social formado por pessoas que, de certo modo, rompem com a estrutura social instituída, que tensionam os modos organizativos da sociedade, mas que, para garantir o direito de se colocar sem amarras sociais, precisam, necessariamente, apropriarem-se da lógica que negam, organizarem-se estruturalmente, com o objetivo de garantir o direito de existência de pessoas supostamente livres.

Um segundo paradoxo do movimento que evidenciamos com a pesquisa, diretamente relacionado com o primeiro, diz respeito à necessidade de ocupar espaços longe das ruas, mesmo sabendo que a ação direta precisa ser realizada nos locais onde as pessoas em situação de rua vivem. De acordo com Saulo, o confronto se dá nas ruas, mas, para solucionar problemas relacionados à falta de políticas públicas para a população de rua, é preciso se organizar como movimento social, institucionalizar-se, adentrar as salas, gabinetes, auditórios, plenárias e outros espaços distantes da rua. É possível compreender, com as tensões apresentadas por Saulo, que o trabalho com as pessoas que vivem em situação semelhante à dele precisa se deslocar para espaços outros; a micropolítica, para reivindicar e consolidar mudanças almejadas, requer lutas macropolíticas, o que os convoca a participar de instâncias decisórias, em âmbitos municipal, estadual e nacional.

Mas essa participação não se traduz em resultados que atendam aos anseios e necessidades das pessoas em situação de rua com a velocidade desejada. Em outras palavras, a transformação social parece ter ritmo contrário ao fluxo da rua, local em que tudo acontece de forma rápida. Evidencia-se, assim, um terceiro paradoxo: convocar as pessoas em situação de rua a investirem em um movimento político que é lento, gradual e árduo pode se configurar como algo oposto ao que algumas delas escolheram para suas vidas e distante do que almejam para o futuro. É comum encontrarmos pessoas que, por não se adaptarem aos padrões tradicionais de vida na sociedade, fizeram das ruas seus espaços de existência. Para essas pessoas, negar a participação em um movimento social é coerente com a postura de vida que escolheram. Mas a garantia de direitos sociais, do direito à cidade e à própria presença nas ruas requer luta e formas de enfrentamento que produzam alguma resposta positiva por parte do Poder Público.

Aorganização em movimento social éum caminho historicamente reconhecido, o que leva as pessoas em situação de rua a optarem por ele. Mas essa opção é, de certo modo, produtora de conflito, vivenciado objetiva e subjetivamente. Afinal, exige um retorno à lógica tradicional, a um modo organizado de luta em que papéis são definidos e hierarquias são construídas. O MNPR se submete a uma organização social de luta, enquadrando-se em um modo estruturado de exigir e conquistar seus direitos, por meio da realização de ações sistematizadas, como as reuniōes semanais. 
Alice, participante da pesquisa e militante do movimento, mulher, negra, 34 anos, sendo 14 destes vividos em situação de rua, levou para o grupo seu incômodo em perceber que sempre há poucas pessoas em situação de rua nos encontros. Ela se queixou de, em alguns momentos, não perceber muito sentido em fazer parte do movimento porque as pessoas não aderem. Saulo pontuou que o MNPR estava perdendo sua identidade, que sentia o movimento polarizado, ocupando duas instituiçôes. ${ }^{4}$ Destacou ser a rua a verdadeira identidade daquele coletivo, contudo ela era deixada de lado, sendo as pessoas que justificavam a existência do movimento não acessadas pelo MNPR.

Eu sei o quanto é difícil pro morador de rua atravessar todo o centro. Os olhares do centro, das pessoas do centro, pra conseguir chegar até a reunião, e que, quando chega, tem que dizer o nome na recepção e dizer que quer ir pra reunião do MNPR. É que esse processo é muito difícil pro morador de rua (Diário de campo, fala de Saulo, maio de 2017).

Também eu, com a fala de Saulo, procurei entender o ponto de vista do outro, no caso das pessoas em situação de rua. As reuniōes semanais do MNPR ocorriam, desde quando comecei a acompanhar o movimento, em um ambiente fechado, por vezes, hostil. Ficava nítido o caráter de favor da instituição ao emprestar um espaço para as reuniōes, além de exigir um tipo de comportamento pouco habitual para os participantes, como o tom de voz baixo. Para chegar até o local, era necessário que as pessoas atravessassem o centro da cidade, saíssem do local costumeiro de passar o dia, transitassem pelas ruas centrais para, enfim, chegarem à sede da instituição. Um percurso pequeno, mas que se configurava como longo e tortuoso para corpos errantes, marginalizados e não desejados, que se chocam com corpos padronizados. Além disso, ao chegar, era necessário se apresentar à recepcionista, que então registrava o nome da pessoa em uma lista de presença e a direcionava à sala de reunióes na qual o movimento estava.

Saulo comenta que esse processo de ir até as reunióes colocava a pessoa em situação de rua em exposição e, por diversos motivos, ela poderia não estar disposta naquele momento. Evidenciava que realizar as reuniões longe dos espaços a que essas pessoas já estavam acostumadas a ocupar provocava uma visibilidade que poderia não ser bem-vinda, ao exigir que saíssem de seus territórios e transitassem por territórios outros, como as ruas do centro, cheias de lojas e transeuntes, o que expunha a pessoa a um contexto não favorável e não desejável. Tal fala provocou questionamentos quanto à exposição e a visibilidade de pessoas em situação de rua que poderiam não se sentir preparadas para isso e expôs o paradoxo em relação às condições que deviam ser superadas para participar do movimento.

4 As reuniōes do MNPR eram realizadas na sede de instituições parceiras. Posteriormente, as reuniões foram transferidas para uma praça na região central da cidade e de grande fluxo de pessoas em situação de rua. 
Comumente ouvimos discursos referindo-se à população de rua como "invisíveis". A inclinação social por invisibilizar essas pessoas está atrelada a uma espécie de cegueira seletiva, na qual o ato de fingir não ver predomina (Delfin, Almeida, \& Imbrizi, 2017, p. 2). Entretanto não é feito o questionamento se essas pessoas desejam se tornar visíveis, qual tipo de visibilidade almejam e como lidam com a visibilidade indesejada. Com base na fala de Saulo, é possível considerar que o desejo de visibilidade pode existir, assim como o desejo de invisibilidade.

Em uma reunião do MNPR, um dos membros contou que estavam fotografando pessoas em situação de rua sem permissão, e protestou: "Tenho o direito de ficar invisível!" (Diário de campo, fala de Augusto, março de 2017). A afirmação categórica negava o lugar de passividade no qual a pessoa em situação de rua era colocada. Reivindicava o lugar de ser humano, capaz de opinar e decidir sobre si próprio, negava a coisificação e objetivação dos corpos que compunham a paisagem urbana, porque aqueles corpos não eram a paisagem em si. Eram pessoas em situação de rua que reivindicavam o direito de permanecerem (in) visíveis, conforme o desejo, a circunstância e o contexto, assim como todas as pessoas que não viviam nas ruas.

Refletir sobre visibilidades e invisibilidades é pensar sobre aquilo que se vê, aquilo que deixa ser visto, aquilo que deixamos de ver e aquilo que nos provoca perder de vista. (In)visibilidade como esse processo que tensiona as possibilidades de olhar e ser olhado, que se configura por meio de "um jogo de sombra e luz: um sujeito, um grupo, seu sofrimento, a violência contra ele e possíveis modos de resistência que só se tornam invisíveis à medida que outros elementos são visibilizados" (Delfin, Almeida, \& Imbrizi, 2017, p. 2). São formas de existências atravessadas pelo desejo de ser visto: visibilidade desejada, ao mesmo tempo, pelo direito de não ser visto: invisibilidade desejada. Os processos de (in) visibilidades (in)desejadas estão imbricados no cenário urbano e na produção de uma sociedade que ainda não reconhece as pessoas em situação de rua como parte de um todo.

A dificuldade dos membros do MNPR em lidar com esses processos de (in) visibilidades vão sendo coordenadas pelas atividades do dia a dia, no cotidiano. A busca por visibilidade em uma esfera tensiona a busca por invisibilidade em outra, o que constitui polos que coexistem na complexa tentativa de garantir o direito a ambas. Eis o quarto paradoxo que identificamos com a pesquisa realizada: o próprio MNPR pode provocar paradoxalmente exposições e visibilidades que algumas pessoas não desejam. Mas havia como minimizar isso: alterar o local das reuniōes era uma estratégia possível para agregar pessoas que ainda não estavam 
preparadas para circular livremente em outros contextos.

Para além da questão territorial, outra reflexão que o MNPR pesquisado realizou sobre a baixa adesão considerava as pessoas em situação de rua pouco empenhadas em lutar por seus direitos. Justificavam que o caráter não assistencialista, não salvacionista e de não ter como foco retirar as pessoas em situação de rua contribuía para que menos pessoas aderissem. $\mathrm{O}$ foco era a luta por direitos sociais, algo realizado de forma lenta e gradativa, que poderia gerar insatisfação ou sentimento de ineficácia para alguns. "O que a gente faz aqui é discutir direito e conquista, por isso não faz tanto sucesso" (Diário de campo, fala de Saulo, março de 2017).

Quando, nas reuniōes do MNPR, havia novas pessoas, o coordenador estadual buscava esclarecer os objetivos do movimento e realizava a fala supracitada para justificar o fato de a reunião estar vazia ou com poucas pessoas em situação de rua.

Em busca de compreender as razões para a baixa adesão ao movimento, esse tema foi levado à tona nas conversas na praça central, local de grande concentração de pessoas em situação de rua. Para algumas pessoas que vivem nas ruas e com as quais conversei, o MNPR era considerado como mais uma instituição não legítima e sem representatividade. Em uma das reuniōes semanais, a falta de notabilidade do MNPR nas ruas foi um tema levado por um grupo de três pessoas em situação de rua que tinham ido pela primeira vez à reunião semanal. "O Movimento não tem credibilidade na rua. Ninguém da rua respeita o movimento" (Diário de campo, novembro de 2016).

A representatividade do MNPR era também questionada por outras pessoas em situação de rua. No diário de campo, foram registradas falas de pessoas que viviam nas ruas, que estavam pela primeira vez na reunião do movimento e que nunca mais voltaram a frequentá-la. Naquele dia, o descontentamento com o MNPR por parte de um grupo de pessoas que viviam em condição de rua foi denunciado, a falta de representatividade foi escancarada. Porém o tema não foi levado em consideração pelos militantes do movimento. Havia divergências pessoais entre os personagens que faziam essa fala-denúncia e os membros efetivos do MNPR, o que fez com que esse tensionamento ao coletivo atravessasse para a esfera pessoal, particular e individual. Então, em vez de absorver a crítica e refletir sobre ela, militantes a rebateram e culpabilizaram as próprias pessoas em situação de rua por não estarem dispostas a lutar. Ainda foi afirmado que pessoas como as que faziam a crítica exigiam resultados rápidos e transformadores do MNPR sem ao menos se colocarem disponíveis para somar ao movimento. 
Talvez, naquele dia, aquelas pessoas estivessem colocando-se disponíveis para aderir à luta traçada pelo MNPR, mas não houve sensibilidade por parte dos membros em acolher as críticas, problematizá-las e aproximar essas pessoas. Ao contrário, a reação de defesa/acusação as afastou e contribuiu para ruir a precária ponte que interligava a rua e o movimento. "Nós que botamos as costas no chão é que devemos ser a base do movimento" (Diário de campo, novembro de 2016).

A fala supracitada, que ocorreu nessa mesma reunião, emergiu em resposta ao fato de alguns membros do MNPR não mais dormirem todos os dias nas ruas, pois conseguiram se organizar e alugar um espaço para viver. A situação de não dormirem mais ao relento, de não "botarem as costas no chão", fez com que algumas pessoas não as considerassem legítimas para ocupar o papel que exerciam no movimento. Mas, apesar disso, as pessoas que não estavam "colocando as costas no chão" ainda tinham uma rotina como se estivessem em situação de rua, pois iam para suas casas apenas para dormir e tomar banho; passavam o dia todo em conjunto com as demais pessoas em situação de rua, alimentavam-se das doações, "mangueavam" e sentiam-se ainda vivendo integralmente nas ruas.

Essa condição é produtora de tensões nas relações com outras pessoas que viviam em situação de rua, pois gerava desconfiança: algumas pessoas afirmavam que o MNPR possuía uma verba financeira e, com esta, os membros pagavam seus aluguéis. Tal argumento foi refutado, pois membros afirmaram que pagavam o aluguel com o benefício assistencial que recebiam do governo federal. ${ }^{6}$

Por mais que, em alguns momentos, as críticas à falta de representatividade não fossem compreendidas, em outros, elas ecoavam e produziam um processo reflexivo de como o MNPR se organizava. Saulo realizava constantemente o movimento de pensar e criticar o modo como agiam, com a intenção de suscitar possíveis soluções. "Temos feito do jeito que a gente critica. Modo do para a rua ao invés de com a rua. Muitos não reconhecem o MNPR por falta de informação, eles falam que a gente não faz junto, que é uma panelinha" (Diário de campo, fala de Saulo, maio de 2017).

Tal discurso enuncia a autocrítica e coloca o próprio MNPR como responsável pelo afastamento e não adesão das pessoas. Em vez de culpabilizar o outro, traz para si as responsabilidades como um coletivo representativo e disposto a realizar mudanças para alterar o cenário de pouca adesão, representatividade, credibilidade e respeito. De acordo com Barros e Kastrup (2009), o fazer "com" é o fazer coletivo, é a participação no processo. No caso do MNPR, o fazer "com"

5 "Manguear" é uma gíria referente à ação de pedir.

6 Os benefícios assistenciais identificados foram o Bolsa-Família e o Benefício de Prestação Continuada (BPC) da Lei Orgânica da Assistência Social (LOAS). Benefícios vigentes no período em que a pesquisa foi realizada, nos anos de 2016 e 2017, durante os governos Dilma Rousseff e Michel Temer. A continuidade de tais benefícios tem sido discutida pelo governo Bolsonaro, com possibilidades de cortes e suspensões. 
é promover a integração das pessoas que vivem em situação de rua no processo de conquistas de direitos, de transformaçōes sociais, é fazer junto, transfigurar as pessoas que vivem nas ruas, passar de meros objetos passivos a membros ativos e atuantes ao que lhes cabe e interessa. Para Macerata (2010, p. 171), o fazer "com" a rua é o fazer "ao lado, o que não é postar-se sobre, acima, hierarquicamente", é compor-se do mesmo território existencial, mesmo que o espaço e tempo sejam diferentes.

O fazer "com" é uma das pautas de luta do MNPR. Ele exige das instâncias políticas sua presença em qualquer assunto que seja relacionado à população de rua, reivindica sua participação na construção de ações, reclama de política feita "para" eles, sem a presença deles. Assim, a fala de Saulo expõe a situação paradoxal que o MNPR assume, ao contradizer o que o define, perpetuar a lógica que busca combater e se distanciar daqueles que justificam sua existência. Eis o quinto paradoxo que identificamos com a pesquisa: as pessoas que estão à frente da luta em prol de condições dignas de existência para pessoas em situação de rua, consideradas seus pares, visto que conseguem sair das ruas, passam a ser vistas como outros, não mais parceiras.

Considerando o cenário em que o MNPR se constitui, cabe salientar que o processo de organização política de pessoas em situação de rua pode se configurar como algo mais complexo quando comparado à organização social de outros grupos. Para Almeida (2015) e Melo (2015), a organização política de pessoas em situação de rua ainda é algo extremamente novo, o que requer intenso trabalho de base para construir um histórico de luta. Para os autores, as pessoas em situação de rua não têm acesso aos direitos básicos e apresentam necessidades a serem sanadas de forma instantânea e imediata, o que justificaria a adesão aos movimentos sociais como algo secundário, pois

Quem vive à margem, lutando dia a dia pela sobrevivência, já tem naturalizado a invisibilidade, o não reconhecimento enquanto sujeitos de direitos, por isso, o despertar da consciência exige insistência e reflexão sobre essas condiçōes, as quais as pessoas em situação de rua vivenciam (Almeida, 2015, p. 93).

Assim, a falta de adesão ao MNPR configura-se como um fenômeno complexo, que não se justifica de maneira simples, pois é atravessada por diferentes razões que compõem as singularidades de cada corpo que constitui a rua. Com as reunióes transferidas para a praça principal da cidade, local em que há grande fluxo e concentração de pessoas em situação de rua, houve aumento da participação nas reuniões e atividades propostas pelo MNPR por parte de seu público-alvo. Esse deslocamento territorial exemplifica um dos paradoxos que caracteriza o próprio MNPR e suas ações. Ou seja, a necessidade de se organizar 
estruturalmente e manter a segurança dos participantes o levou a usar um espaço institucional para suas reuniōes; porém a pouca adesão de pessoas em situação de rua às atividades colocava em xeque o próprio movimento e o distanciava de seu público-alvo, das pessoas que justificam sua própria razão de ser/existir.

Enquanto, para alguns participantes da pesquisa, o MNPR não se configurava como um espaço legítimo de luta das pessoas em situação de rua, para outras, ocupar espaços, institucionalizar-se e militar possibilitou outras formas de se colocar no mundo. "Eu achava que eu era ninguém, agora as pessoas falam comigo e eu me sinto importante. O MNPR ajuda na minha redução de danos, ajuda eu não voltar pra rua" (Diário de campo, fala da Alice, março de 2017).

Alice, que se mantinha acorrentada ao sentimento de não ser alguém, tinha como única possibilidade ser ninguém. Inevitável não os lembrarmos do poema de Galeano (2010) em que "os ninguéns: os filhos de ninguém, os donos de nada" são aqueles "que custam menos que a bala que os mata" (p. 71). A fala de Alice nos leva a pensar que, a partir do momento em que se vinculou ao MNPR, passou a ser gente, saiu da condição de ninguém para a de alguém que agora se sentia importante, era vista e ouvida. Baumgarten (2013) afirma que o envolvimento de pessoas em situação de rua em mobilizações políticas configura-se como uma forma também de resgate de autoestima e recuperação de uma vida estável.

Talvez, para a sociedade, Alice continue enquadrada como um ninguém, "morrendo a vida, fodido e mal pagos" (Galeano, 2010, p. 71), e sua luta visa a buscar o reconhecimento e a transformação social dos vários, várias ninguéns. Sua mudança pessoal já ocorreu, pois se enxergava, se posicionava e se sentia de modo diferente. Isso também aconteceu com Sandro: "Conhecer o MNPR foi bom porque me deu mais segurança para conhecer esse mundo da rua e não me sentir tão sozinho [. . .] saber que tem outros igual a mim" (Diário de campo, fala de Sandro, junho de 2017).

Para Sandro, fazer parte do MNPR possibilitou o reconhecimento de pessoas semelhantes a ele. Favoreceu a construção de vínculos com outras pessoas que viviam nas ruas. Reconfigurou a rua como lugar de solidão e insegurança para um lugar coletivo e seguro. A fala de Sandro nos remete à importância dos agrupamentos sociais, dos coletivos de pessoas que partilham a mesma realidade.

O MNPR consiste, pois, em um dispositivo que fortalece e busca garantir a existência de pessoas em situação de rua em uma sociedade na qual a diferença ainda é entendida de forma negativa. Ao estar em situação de rua, um dos participantes da pesquisa assumiu ter um posicionamento político alinhado com o anarquismo, porém se filiou ao movimento social de rua organizado, MNPR, 
como uma maneira de garantir seu modo de viver.

O MNPR também promove uma visibilidade desejada em relação ao olhar do outro sobre a pessoa em situação de rua, eleva a autoestima, constrói a imagem de uma pessoa que conhece seus direitos e luta por estes, afasta o estereótipo de "morador de rua", produz novos e diferentes olhares, tanto no outro quanto na pessoa em situação de rua.

Eu estive na calçada fumando crack várias vezes, e hoje, graças a pessoas e ao movimento, eu começo a ter uma outra visão da vida. [. . .] O movimento me deu oportunidade de mostrar não para os outros, mas pra mim, que eu posso fazer uma coisinha um pouquinho melhor. [. . .] Quando faço fala de movimento, eu tenho que me modificar todinho, porque não é mais a minha fala, é nós. E esse processo é o que me fez sentir mais humano, apesar que eu erro a toneladas ainda. [. . . ] A minha vivência mesmo é essa [. . .] É a vivência de luta, resistência, de estar nesse Movimento. [. . .] Eu ouvi uma frase do companheiro que falou assim: "a partir do momento que você entra dentro de um movimento social, você não tem dois lados, do militante e o Saulo. Tu vai ser os dois. As pessoas não vão mais te ver como Saulo que tem a sua vida, e Saulo que tem o movimento, não há mais como justificar. Se você brigou na rua, foi o Saulo do Movimento; se te pegar fumando crack, foi o Saulo do Movimento; se tava lá discutindo, é o Saulo do Movimento”. Eu deixei de ser, muitas vezes, o que eu realmente sou. Gosto de usar droga pra caramba, mas tive que começar a me modificar (Diário de campo, fala de Saulo, junho de 2017).

A fala de Saulo evoca a condição de respondibilidade da existência humana. Ao dizer que "não há mais como justificar", o interlocutor da pesquisa assume uma postura sobretudo ativa de suas tomadas de decisões, de suas ações, de sua condição de vida, de sua própria existência. Para Bakhtin (2010), não há álibi para existência, ou seja: nossos atos, açôes, atitudes são responsáveis, fazem parte de nossa singularidade, da unicidade da existência. Assim, Saulo evidencia sua implicação no MNPR, o seu não álibi em relação à vida e, consequentemente, ao movimento social, visto que ambos se misturam e se compõem. Essa participação incumbida revela um ato concreto, em que todos os sentimentos, pensamentos, desejos são um ato "ativamente responsável" (Bakhtin, 2010, p. 118). Para o autor, o ato responsável é "o ato baseado no reconhecimento desta obrigatória singularidade. É essa afirmação do meu não álibi no existir que constitui a base da existência sendo tanto dada como sendo também real e forçosamente projetada como algo ainda por ser alcançado" (p. 99, grifos do autor).

A importância do MNPR na vida de algumas pessoas em situação de rua foi evidenciada nos fragmentos de diários de campo aqui expostos. O MNPR assume múltiplos lugares, provoca diferentes reaçôes, pode ser considerado tanto como o espaço que busca garantir o direito de viver na rua para alguns como também meio para se organizar e sair das ruas. Para outros, em contrapartida, pode ser 
apontado como ilegítimo e desnecessário. Maheirie (2008) pontua a importância de considerar os movimentos sociais como "um processo contínuo de construção e desconstrução, na ambiguidade presente e inevitável que lhe compõe, implicando num trabalho de unificação da diversidade, incorporando a diferenciação" (p. 54). Essa ambiguidade foi visibilizada pelos próprios participantes no decorrer da pesquisa, condição fundamental para o fortalecimento da luta e a unificação de esforços em prol da conquista de direitos.

\section{CONSIDERAÇÕES FINAIS}

A pesquisa realizada evidencia que a luta do MNPR é complexa e marcada por uma série de paradoxos:

1) a condição de incômodo e, ao mesmo tempo, de reconhecimento da importância do lugar ocupado pela liderança do movimento;

2) a tensão entre estar nas ruas e estar nos espaços institucionalizados de luta;

3) a contradição entre projetos de vida singulares e a necessidade de luta por mudanças para todos, todas;

4) a tensão visibilidade e invisibilidade das pessoas em situação de rua;

5) a contradição entre viver nas ruas e poder/querer sair dessa condição, com o risco de não ser mais reconhecido, reconhecida pelos pares e participar de sua luta.

Foi possível constatar que a própria existência do MNPR como movimento social instituído é paradoxal: é composto por e voltado para pessoas que questionam padrões sociais, mas precisa, de certo modo, adequar-se a padróes de institucionalização, posto serem estes condição para alguma escuta, para a reivindicação do direito de seus participantes permanecerem à margem se assim o desejarem. As tensões visibilizadas entre as pessoas em situação de rua que não participam do movimento com relação ao MNPR são, de certo modo, consoantes com tensões constitutivas do próprio MNPR.

Esses paradoxos, por sua vez, visibilizam tensões que não dizem respeito somente a esse movimento, mas que atravessam movimentos sociais de diferentes nichos, conforme apontado por Lemóes (2019). Almeida (2015) pontua que o MNPR necessita ainda de aperfeiçoamentos teórico e político, bem como apresenta fragilidades em sua constituição, mas ressalta o papel importante que ocupa na 
luta por direitos. Concordamos com a autora e ressaltamos a importância do MNPR na luta por direitos sociais, políticos e humanos à população em situação de rua.

Para finalizar, destacamos que a pesquisa realizada soma esforços às investigações sobre MNPR que destacam sua importância (De Lucca, 2016; Freitas, 2016; Lemões, 2019; Melo, 2015; Melo, 2016; Santos, 2017; Silva, 2017). Os paradoxos evidenciados com a pesquisa se apresentam como expressão do caráter inventivo que o movimento vem assumindo, como algo que faz parte do processo de se constituir como movimento social, imbricado nas contradições sociais existentes. Visibilizam, por conseguinte, a dinâmica e a intensidade da própria luta de um movimento que se faz "com", renovando-se constantemente. 


\section{REFERÊNCIAS}

Aguiar, K. F., \& Rocha, M. L. (2007). Micropolítica e o exercício da pesquisaintervenção: referenciais e dispositivos em análise. Psicologia: Ciência e Profissão, 27(4), 648-663. Recuperado a partir de_http://www.scielo.br/scielo. php?script=sci_abstract $\&$ pid $=$ S1414-98932007000400007\&lng=pt\&nrm $=$ is o\&tlng=pt

Almeida, H. T. (2015). O processo de organização política da população em situação de rua e as particularidades de Natal/RN. (Dissertação de Mestrado). Universidade Federal do Rio Grande do Norte, Natal. Recuperado a partir de https://sigaa.ufrn.br/sigaa/public/programa/defesas.jsf?lc=pt_BR\&id=376

Almeida, H. T., Medeiros, F. C., \& Barbosa, A. C. (2014). O Centro de Referência em Direitos Humanos e a população em situação de rua de Natal/ RN: a luta dos (in)visíveis urbanos. In I.L. Paiva, C. Souza, D.A. Valença \& A. Araújo (Orgs.). Direitos humanos e práxis: experiência do CRDH-RN. (Vol. 1, pp. 151-175). Natal: EdUFRN.

Bakhtin, M. M. (2010). Para uma filosofia do ato responsável. V. Miotello, \& C. A. Faraco (Trads.). São Carlos: Pedro \& João.

Bakhtin, M. M. (2011). Estética da criação verbal. P. Bezerra. (Trad.)(6a ed.). São Paulo: Martins Fontes.

Barros, L. P., \& Kastrup, V. (2009). Cartografar é acompanhar processos. In E. Passos, V. Kastrup, \& L. Escóssia. Pistas do método da cartografia: pesquisaintervenção e produção de subjetividade. (pp. 52-75). Porto Alegre: Sulina.

Baumgarten, B. (2013). Political participation of the homeless in Brazil. CIES e-working Paper, 171, 1-14. Recuperado a partir de https://repositorio.iscteiul.pt/handle/10071/9859

Conselho Federal de Psicologia. (2015). A Psicologia e a população em situação de rua: novas propostas, velhos desafios. Belo Horizonte: CRP 04.

Decreto no 7.053, de 23 de dezembro de 2009. (2009, 23 dezembro). Institui a Política Nacional para a População em Situação de Rua e seu Comitê Intersetorial de Acompanhamento e Monitoramento, e dá outras providências. Diário Oficial da União, Brasília. Recuperado a partir de http://www.planalto. gov.br/ccivil_03/_Ato2007-2010/2009/Decreto/D7053.htm 
Delfin, L, Almeida, L. A. M., \& Imbrizi, J. M. (2017). A rua como palco: arte e (in)visibilidade social. Psicologia \& Sociedade, 29, 1-10. Recuperado a partir de https://dx.doi.org/10.1590/1807-0310/2017v29158583

De Lucca, D. (2016). Morte e vida nas ruas de São Paulo: a biopolítica vista do centro. In T. Rui, M. Martinez , \& G. Feltran. (Orgs), Novas faces da vida nas ruas. (pp. 23-43). São Carlos: EdUFSCar.

Freitas, M. V. O. (2016). Traçando os fios de uma história: população em situação de rua na cidade de São Paulo (1970-2005). (Tese de Doutorado). Universidade de Brasília, Programa de Pós-Graduação em História, Brasília. Recuperado a partir de http://repositorio.unb.br/handle/10482/21069

Galeano, E. (2010). O livro dos abraços. Porto Alegre: L\&PM.

Lemões, T. (2019). Hierarquia, contestação e igualdade: a produção da militância política para a população de rua no Brasil. Civitas - Revista de Ciências Sociais, 19(1), 123-141. Recuperado a partir de http://www.scielo.br/pdf/civitas/ v19n1/1984-7289-civitas-19-01-0123.pdf

Macerata, I. M. (2010). “.. como bruxos maneando ferozes”: relaçôes de cuidado $e$ de controle no fio da navalha: experiência "psi" em dispositivo da politica de assistência social para crianças e adolescentes em situação de rua. (Dissertação de Mestrado). Universidade Federal Fluminense, Programa de Pós-Graduação em Psicologia, Niterói. Recuperado a partir de http://www.slab.uff.br/psm/ uploads/2010_d_Iaca.pdf

Machado, J. P., \& Zanella, A. V. (2019). Bakhtin, Ciências Humanas e Psicologia: diálogos sobre epistemologia e pesquisa. Psicologia \& Sociedade, 31, 1-17. Recuperado a partir de https://dx.doi.org/10.1590/18070310/2019v31166423

Maheirie, K. (2008). Identidade: o processo de exclusão/inclusão na ambiguidade dos movimentos sociais. In A. V. Zanella, M. J. T. Siqueira, L. A. Lhullier, \& S. I. Molon (Orgs.), Psicologia e práticas sociais. (pp. 49-56). Rio de Janeiro: Centro Edelstein de Pesquisas Sociais. Recuperado a partir de http://books. scielo.org/id/886qz/06

Melo, T. (2016). "Da rua pra rua”: novas configurações políticas a partir do Movimento Nacional da População de Rua (MNPR). In T. Rui, M. Martinez, \& G. Feltran (Orgs.), Novas faces da vida nas ruas. (pp. 45-65). São Carlos: EdUFSCar. 
Melo, T. H. A. G. (2015). População em situação de rua e o "direito a ter direitos". Novos Debates: Fórum de Debates em Antropologia, 2(1), 198-206. Recuperado a partir de http://novosdebates.abant.org.br/index.php/numeros-anteriores/ v2n1/forum-v2n1?id=168:populacao-em-situacao-de-rua-e-o-direito-a-terdireitos

Paulon, S. M. (2005). A análise de implicação com ferramenta na pesquisaintervenção. Psicologia \& Sociedade, 17(3), 18-25. Recuperado a partir de http://www.scielo.br/scielo.php?script=sci_arttext\&pid=S0102$71822005000300003 \& \operatorname{lng}=\mathrm{pt} \& \mathrm{nrm}=$ iso $\&$ tlng=pt

Rocha, M. L., \& Aguiar, K. F. (2003). Pesquisa-intervenção e a produção de novas análises. Psicologia: Ciência e Profissão, 23(4), 64-73. Recuperado a partir de http://www.scielo.br/scielo.php?script=sci_abstract\&pid=S141498932003000400010\&lng=pt\&nrm=iso\&tlng=pt

Santos, G. P. (2017). A voz da situação de rua na agenda de mudança social no Brasil: um estudo discursivo crítico sobre o Movimento Nacional da População em Situação de Rua (MNPR). (Tese de Doutorado). Universidade de Brasília, Programa de Pós-Graduação em Linguística, Brasília. Recuperado a partir de http://repositorio.unb.br/handle/10482/24869

Sicari, A. A. (2018). A cidade, a rua, as pessoas em situação de rua: (in)visibilidades e a luta por direitos. (Dissertação de Mestrado). Universidade Federal de Santa Catarina, Programa de Pós-Graduação em Psicologia, Florianópolis. Recuperadoa partirdehttps://sucupira.capes.gov.br/sucupira/public/consultas/ coleta/trabalhoConclusao/viewTrabalhoConclusao.jsf?popup=true\&id_ trabalho $=5972210$

Silva, T. L. (2017). De vidas infames à máquina de guerra: etnografia de uma luta por direitos. (Tese de Doutorado). Universidade Federal do Rio Grande do Sul, Programa de Pós-Graduação em Antropologia Social, Porto Alegre. Recuperado a partir de https://www.lume.ufrgs.br/handle/10183/172916 